\title{
Model konseptual IMTA dan RIMTA pada budidaya lobster di karamba jaring apung (KJA)
}

\section{IMTA and RIMTA conceptual model on lobster cultivation in floating net cages}

\author{
R. M. Rofiq ${ }^{1}$, M. Rifqi ${ }^{*}$ \\ 1Direktorat Jenderal Perikanan Budidaya, Kementerian Kelautan dan Perikanan, Jakarta, Indonesia
}

\begin{abstract}
Abstrak.
Untuk mengoptimalkan manfaat ekonomi keberadaan sumberdaya benih lobster di perairan Indonesia, maka pengembangan budidaya lobster oleh pembudidaya dan pelaku usaha dalam negeri perlu segera dilakukan. Mempertimbangkan perkembangan adopsi teknologi budidaya lobster saat ini, maka segmen usaha pendederan perlu dilaksanakan pada fasilitas unit pelaksana teknis (UPT) Direktorat Jenderal Perikanan Budidaya, segmen usaha selanjutnya yaitu pembesaran lobster di Karamba Jaring Apung (KJA) laut dapat melibatkan masyarakat/ pembudidaya dan pelaku usaha. Implementasi Integrated Multi Tropic Aquaculture (IMTA) pada budidaya lobster baik pada skala unit maupun kawasan dapat mewujudkan prinsip keberlanjutan, mengoptimalkan pemanfaatan sumberdaya, meningkatkan penerimaan pembudidaya dan pelibatan masyarakat lebih banyak, menyediakan jasa lingkungan (environmental service) dari komoditas ekstraktif serta sekaligus sebagai kontribusi perikanan budidaya dalam mitigasi emisi gas rumah kaca. Beberapa komoditas ekstraktif yang berpotensi dibudidayakan bersama lobster adalah rumput laut, kekerangan, teripang dan beberapa jenis ikan bertropik level rendah. Dibutuhkan penelitian terkait pakan yang efektif untuk benih dan pembesaran serta manajemennya, parameter lingkungan yang optimal, metode budidaya, jenis hama dan penyakit lobster serta penanggulangannya.
\end{abstract}

Kata kunci: lobster, ecosystem approach, environmental services

\begin{abstract}
.
In order to optimize the economic value of tropical lobster resources in Indonesian waters, it is important to immediately develop lobster culture, both of domestic farmers and businesses. Based on existing adoption of tropical lobster culture technology, the business segment on tropical lobster culture can be divided into two types, those are rearing stages should be implemented at the technical implementation unit (UPT) facilities of the Directorate General of Aquaculture Fisheries, while the next stages is the grow up of lobsters in the floating net cages can involve the local coastal community or farmers and businesses. Integrated Multi Tropic Aquaculture (IMTA) implementation on lobster cultivation both on unit and regional scale can realize the principle of sustainability, optimize resource utilization, increase the acceptance of farmers and community involvement, provide environmental services of extractive commodities and at the same time as the contribution of aquaculture fisheries in the mitigation of greenhouse gas emissions. Some extractive commodities that are potentially cultured with lobster are seaweed, shellfish, sea cucumbers and some types of low-level tropical fish. It takes research related to effective feed for seed and grow up and its management, optimal environmental parameters, cultivation methods, types of pests and diseases of lobsters and their treatment.
\end{abstract}

Keywords: lobster, ecosystem approach, environmental services

\section{PENDAHULUAN}

Sejalan dengan perubahan kebijakan penanganan sumberdaya benih lobster di perairan wilayah Republik Indonesia, perlu dioptimalkan kegiatan pembudidayaan lobster dalam negeri diantaranya metode Karamba Jaring Apung (KJA). Kebijakan Kementerian Kelautan dan Perikanan (KKP) yang baru mengoptimalkan manfaat untuk perekonomian dalam negeri dengan pelarangan ekspor benih lobster dan mengembangkan kegiatan pembudidayaannya. Melalui kebijakan ini, ke depan Indonesia mengekspor lobster hidup pada ukuran

\footnotetext{
${ }^{*}$ Korespondensi Penulis

Email : rifqi_muhammad1975@apps.ipb.ac.id
} 
konsumsi (KKP 2021a). Dengan demikian, sumberdaya lobster dapat meningkatkan penerimaan negara dari pajak dan devisa, menyediakan lapangan usaha dan investasi bagi pelaku usaha, menyediakan lapangan pekerjaan bagi masyarakat, serta memberikan efek pengganda bagi perekonomian daerah.

Keberlanjutan jangka panjang usaha budidaya lobster di KJA dapat dilakukan dengan mengimplementasikan model kawasan budidaya multispecies dan multitropic (Alexander et al. 2015; Park et al. 2018) menggunakan ecosystem-based approach to aquaculture (Salin and Ataguba 2018). Pendekatan tersebut juga dapat mewujudkan manfaat total (lingkungan, ekonomi dan sosial) (Yu et al. 2017). Kajian yang ada menyimpulkan bahwa kawasan budidaya yang dikembangkan secara monospecies atau monoculture berpotensi menyebabkan akumulasi nutrien (Park et al. 2018) dan dampak negatif lainnya (Yu et al. 2017), sehingga pada akhirnya menimbulkan eutrofikasi dan permasalahan lingkungan. Monoculture memberikan keuntungan yang lebih besar bagi individu pembudidaya dan pelaku usaha, namun Integrated Multi Tropic Aquaculture (IMTA) memiliki eksternalitas lingkungan yang positif dan manfaat sosial yang lebih besar (Yu et al. 2017). Sesuai dengan karakteristik masingmasing lokasi pengembangan budidaya lobster, dapat dilakukan pendekatan IMTA dan RIMTA supaya memberikan manfaat seluas-luasnya bagi masyarakat.

\section{METODOLOGI}

Model konseptual ini disusun berdasarkan analisis terhadap hasil studi literatur yang terdiri atas 35 jurnal, 1 buku dan 4 dokumen lainnya (sebagaimana disebutkan pada Daftar Pustaka). Hasil analisis yang dilakukan selanjutnya diuraikan secara deskriptif pada hasil dan pembahasan.

\section{HASIL DAN PEMBAHASAN}

\subsection{Budidaya Lobster}

Beberapa sentra budidaya lobster di KJA yang mulai berkembang saat ini adalah di Teluk Gerubuk, Provinsi NTB dan beberapa lokasi Unit Pelaksana Teknis (UPT) Direktorat Jenderal Perikanan Budidaya yang menangani komoditas laut. Berdasarkan penelitian dan informasi yang diperoleh, pendederan benih lobster berukuran sekitar 0,1 gram sampai 5-8 gram selama 70 hari, kelangsungan hidupnya berkisar 45-50\% (KKP 2021b). Pembesaran lobster yang dilakukan pada KJA dengan jaring tenggelam di kedalaman 6-8 $\mathrm{m}$, tebar 20 ekor per $\mathrm{m}^{3}$, ukuran benih 50-60 gram dan dipelihara selama 6-7 bulan menghasilkan lobster dengan berat rata-rata 250 gram dengan kelangsungan hidup mencapai 90\% (KKP 2021b). Pembesaran lobster metode kompartemen dasar berbentuk silinder (volume 200 liter dan diameter $3 \mathrm{~cm}$ ) sesuai untuk kontur dasar perairan Pantai Sepanjang Yogyakarta (Anissah et al. 2015). 
Untuk itu teknologi pembudidayaan lobster dan segmentasi usahanya perlu terus dikembangkan, supaya kelangsungan hidup tinggi dan pertumbuhan cepat, sehingga usaha pembudidayaan lobster semakin efisien dan paket teknologinya dapat diadopsi pembudidaya. Jangka pendek, UPT Direktorat Jenderal Perikanan Budidaya dioptimalkan sebagai lokasi proses pendederan untuk menyiapkan benih ukuran siap tebar. Pembesaran lobster di KJA dapat dilakukan oleh pembudidaya dan masyarakat.

\subsection{Budidaya ikan metode KJA yang berlanjutan}

Memperhatikan perkembangan kawasan budidaya ikan di KJA baik di perairan umum darat maupun laut, dapat disimpulkan bahwa penentuan daya dukung dan daya tampung lingkungan serta pengaturan tata letak sesuai peruntukan ruang atau muka air perlu dilakukan sejak awal. Selanjutnya untuk keberlanjutan kawasan budidaya tersebut perlu diminimalisir pelepasan effluent dan cemaran terhadap perairan. Daya dukung dan daya tampung suatu perairan bersifat dinamis, dengan rekayasa teknologi keduanya dapat ditingkatkan. Pengurangan akumulasi bahan organik dan nutrien ke badan air dapat dikendalikan dengan metode bioremediasi (Lamprianidou et al. 2015).

FAO mencanangkan blue growth initiative untuk produksi bahan pangan kawasan Asia Pasifik untuk meningkatkan keberlanjutan penggunaan sumberdaya alam dan menjamin kelangsungan kehidupan masyarakat, melalui pengurangan dampak lingkungan dan sosial intensifikasi perikanan budidaya dan menginisiasi inovasi teknologi dan manajemen praktis budidaya. Keberlanjutan lingkungan budidaya merupakan issue yang kompleks, mencakup dampak lokal atau setempat seperti perubahan struktur dan komposisi bentos, wilayah (regional) seperti eutrofikasi dan global seperti penangkapan ikan sebagai sumber protein pakan ikan serta dari operasional budidaya seperti emisi limbah dan proses industri sepanjang rantai nilai (Chary et al. 2020).

Untuk keberlanjutan pertumbuhan usaha pembudidayaan ikan maka dampak lingkungan yang ditimbulkan perlu diminimalisir (Ahmed et al. 2018). Valenti et al. (2018) mengembangkan indikator kuantitatif yang komprehensif untuk mengukur keberlanjutan usaha budidaya yaitu indikator ekologi, ekonomi dan sosial. Indikator ekologi berkaitan dengan efisiensi penggunaan sumberdaya, pelepasan polutan dan produk sampingan yang tidak digunakan, serta risiko tekanan terhadap biodiversitas perairan. Indikator ekonomi berkaitan dengan efisiensi penggunaan sumberdaya keuangan, kelayakan ekonomi, serta ketahanan dan kapasitas dalam menyerap biaya eksternal negatif dan menghasilkan dana untuk reinvestasi. Indikator sosial berkaitan dengan manfaat bagi masyarakat setempat seperti penyediaan lapangan pekerjaan dan keamanan pangan, pemerataan pendapatan, serta kesetaraan peluang \& inklusif. 
Integrated Multi Tropic Aquaculture (IMTA) adalah budidaya terintegrasi beberapa komoditas (spesies) dari tingkat tropik yang berbeda (Kleitou et al. 2018) yang mengoptimalkan penggunaan nutrien dan energi (Galasso et al. 2020), sehingga bermanfaat untuk penyelesaian masalah akumulasi nutrien di lokasi budidaya laut yang intensif (Lamprianidou et al. 2015), menjadi salah satu cara untuk keberlanjutan perikanan budidaya jangka panjang (long-term) (Alexander et al. 2015) sekaligus mitigasi perubahan iklim (Raul et al. 2020), sebagai balanced ecosystem management approach pada model pengembangan perikanan budidaya (Troell et al. 2009) dan mewujudkan keberlanjutan lingkungan dan ekonomi (Park et al. 2018). IMTA telah lama diimplementasi di Asia, terbukti dapat mewujudkan keberlanjutan perikanan budidaya karena berpotensi mendorong efisiensi ekologi, diterima lingkungan, diversifikasi produk, keuntungan dan manfaat sosial (Kleitou et al. 2018).

Diskusi keberlanjutan usaha pembudidayaan ikan selama ini pada umumnya luput dalam mempertimbangkan potensi dampak negatif dari perubahan iklim. Perubahan iklim dan segala dampak yang ditimbulkan akan menentukan kelangsungan dan keberlanjutan usaha pembudidayaan ikan (Ahmed et al. 2018), termasuk komoditas laut dengan metode KJA. Diantara dampak perubahan iklim di Indonesia adalah potensi gelombang ekstrem dapat mengalami peningkatan 1,0-1,5 m dan rata-rata kenaikan muka laut (sea level rise) $0,9 \mathrm{~cm}$ per tahun (Bappenas 2021), intrusi air laut, asidifikasi serta bencana alam (Hossain et al. 2021). Untuk keberlanjutan jangka panjang maka perikanan budidaya berkepentingan dan perlu mempertimbangkan permasalahan perubahan iklim.

\subsection{Implementasi IMTA dan RIMTA pada Budidaya Lobster}

Implementasi Integrated Multi Tropic Aquaculture (IMTA) pada unit budidaya dan Regional Integrated Multi Tropic Aquaculture (RIMTA) pada kawasan budidaya memungkinkan komoditas ekstraktif (seperti rumput laut dan kekerangan) mengekstrak nutrisi dari buangan (effluent) komoditas utama (seperti lobster) (Neori et al. 2012), atau daur ulang limbah nutrisi dari komoditas tingkat tropik tinggi ke komoditas tingkat tropik lebih rendah yang bernilai ekonomis (Troell et al. 2009). Skema konsep implementasi IMTA pada kawasan budidaya lobster diilustrasikan melalui Gambar 1. Penggunaan bulu babi dan teripang sebagai komoditas ekstraktif IMTA juga cukup efektif memanfaatkan energi dan nutrisi dari komoditas utama (Israel et al. 2019). Dua komoditas tersebut juga terbukti sebagai suatu IMTA yang efektif, dengan bulu babi sebagai komoditas utamanya (Grosso et al. 2021). 


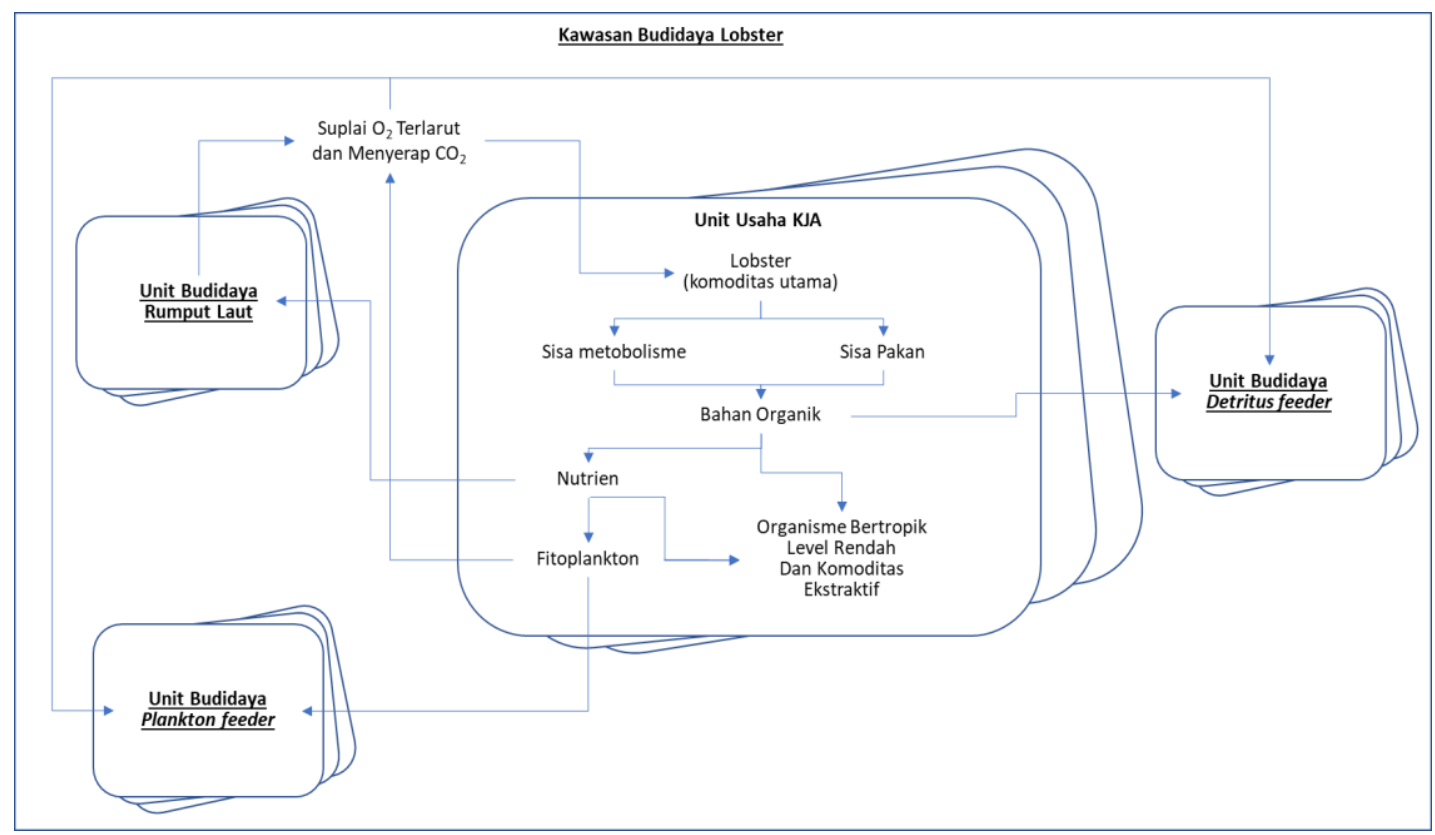

Gambar 1. Skema konsep implementasi IMTA pada kawasan budidaya lobster.

IMTA dan RIMTA salah satu cara untuk memitigasi pelepasan limbah budidaya, mengurangi jejak ekologi (ecological footprint), diversifikasi nilai ekonomi dan meningkatkan keberterimaan sosial sistem budidaya ikan (Troell et al. 2009), mengontrol biofouling (Sterling et al. 2016) dan pengelolaan endapan (Shpigel et al. 2016) di perairan lokasi budidaya, serta sebagai cara biomitigasi limbah budidaya dan mengurangi serangan penyakit (Granada et al. 2018). Dengan model IMTA dan RIMTA, penerapan pendekatan remediasi berpotensi memberikan tambahan penerimaan (revenue) dari nilai hasil panen komoditas ekstraktif (Grosso et al. 2021). Disamping itu, dari perspektif sosial terdapat nilai manfaat jasa lingkungan (environmental services) dari komoditas ekstraktif yang dapat divaluasi menggunakan pendekatan ekonomi lingkungan.

Sebagian besar kajian fokus implementasi IMTA adalah pada budidaya ikan di daratan, hanya sebagian kecil saja yang mengkaji peluang IMTA dan RIMTA di perairan umum seperti lautan (Troell et al. 2009). Komoditas ekstraktif yang berpotensi dikombinasikan pemeliharaannya pada kawasan budidaya laut adalah kekerangan, ganggang dan rumput laut, serta teripang (Nelson et al. 2012). Teripang yang dibudidayakan di kolom air di bawah KJA sebagai komoditas IMTA potensial memiliki kelangsungan hidup dan pertumbuhan yang lebih baik (Yokohama 2012). Pemilihan beberapa komoditas budidaya laut yang toleran terhadap perubahan salinitas dapat menjadi salah satu strategi adaptasi perikanan budidaya terhadap dampak perubahan iklim (Hossain et al. 2021). 
Integrasi pengembangan budidaya lobster dengan rumput laut, kekerangan dan beberapa jenis ikan bertropik level rendah pada satu unit atau kawasan budidaya dapat meningkatkan manfaat ekonomi (nilai produksi komoditas ekstraktif), pengendalian pelepasan limbah budidaya ke perairan, manfaat berupa jasa lingkungan (environmental services) serta meningkatkan simpanan karbon berupa biomassa dan serapan karbon pada komoditas rumput laut. Rumput laut terbukti efektif sebagai filter alami untuk nitrat dan amonia, tetapi tidak efektif terhadap nitrit dan fosfat (Largo et al. 2016). Budidaya rumput laut juga terbukti signifikan sebagai habitat bagi fauna yang aktif bergerak (mobile faunal) (Visch et al. 2020).

Bahan organik dan nutrien yang terbentuk dari sisa metabolisme dan pakan yang tidak termanfaatkan oleh lobster yang seharusnya terakumulasi dalam perairan, dimanfaatkan oleh komoditas ekstraktif untuk pertumbuhannya dan organisme akuatik lainnya yang berasosiasi. Oleh karena itu, diharapkan keberadaan budidaya lobster yang menerapkan IMTA dan RIMTA tidak menyebabkan eutrofikasi. Kandungan bahan organik yang tinggi pada suatu perairan akan menurunkan kandungan oksigen terlarut karena akibat proses penguraian oleh mikroorganisme, disamping itu berpotensi pula terbentuk gas rumah kaca yang diemisikan ke atmosfer (Rifqi et al. 2020a; Rifqi et al. 2020b). Manfaat lain budidaya rumput laut dan beberapa jenis ganggang lainnya sebagai komoditas ekstraktif pada pendekatan IMTA adalah sebagai penyedia oksigen terlarut dari aktivitas fotosintesis (Reid et al. 2013; Visch et al. 2020).

Pada implementasinya, masing-masing pembudidaya menerapkan IMTA pada unit budidaya atau memelihara komoditas ekstraktif pada suatu kawasan terbatas sesuai dengan kemampuan adopsi teknologi dan permodalan. Shpigel et al. (2018) merekomendasikan perbandingan luas permukaan perairan untuk tiga kelompok komoditas sistem IMTA adalah 1:3:4 secara berurutan untuk ikan, Ulva lactuca dan bulu babi. Rasio komoditas utama dengan komoditas ekstraktif pada IMTA tergantung pada komposisi spesies, teknologi yang diaplikasikan dan kondisi lingkungan budidaya (Lamprianidou et al 2015). Pendekatan dynamic energy budget (DEB) adalah model yang dapat digunakan untuk mengestimasi kapasitas bioremidiasi pada suatu IMTA (Galasso et al. 2020).

IMTA terbukti sebagai pendekatan budidaya laut berkelanjutan yang penerapannya terbuka luas di perairan umum China (Shi et al. 2013). Dengan karakteristik biofisik dan kimia perairan tropis Indonesia, implementasi IMTA dan RIMTA seharusnya berpeluang lebih besar dengan pilihan komoditas yang lebih beragam. Dibutuhkan dukungan penelitian terkait pakan yang efektif untuk benih dan pembesaran serta manajemennya, parameter lingkungan yang optimal, metode budidaya, serta jenis hama \& penyakit dan penanggulangannya. 
Farm Aquaculture Resource Management (FARM) adalah model kerangka berpikir untuk menganalisis potensi ekologi dan ekonomi IMTA pada skala unit budidaya dan kawasan perairan (Cubillo et al. 2016). IMTA yang dirancang pada suatu kawasan perairan yang luas seperti teluk dan laguna disebut Sans-Lazaro and Sanches-Jerez (2020) sebagai RIMTA. RIMTA disimpulkan (Sans-Lazaro and Sanches-Jerez 2020) berkelanjutan jangka waktu lebih panjang karena memasukkan aspek spasial dan faktor eksternal seperti aktivitas lain yang berkontribusi menurunkan kualitas lingkungan lokasi budidaya dalam penyusunan konsep pengembangannya. Untuk mendorong pengembangan IMTA dan RIMTA diperlukan dukungan kebijakan ekonomi seperti perpajakan atau skema perdagangan kuota nutrien (Sans-Lazaro and Sanches-Jerez 2020).

Penerapan model IMTA pada kawasan budidaya perairan umum telah berhasil dikembangkan secara komersial skala industri di China dan tahap komersialisasi di Chili, Kanada dan USA (Troell et al. 2009) serta Siprus, Irlandia, Italia dan Skotlandia (Alexander and Hughes 2017). IMTA juga telah diimplementasikan oleh produsen marikultur utama dunia seperti Kanada (Nelson et al. 2012), Norwegia (Handa et al. 2012), Jepang (Yokohama 2012), Israel (Ben-Ari et al. 2014), serta Filipina (Largo et al. 2016). Model IMTA sejalan dengan fokus kebijakan Uni Eropa terkait keberlanjutan lingkungan dan inovasi teknologi, akan tetapi terdapat hambatan terkait kerangka peraturan yang kompleks dan luas (Alexander et al. 2015).

Terdapat 3 (tiga) kunci sukses penerapan IMTA dalam suatu konsep pengembangan perikanan budidaya, yaitu: lebih baik memilih komoditas ekstraktif yang endemis setempat, identifikasi sistem yang tepat menggunakan metode uji coba (trial and error) serta penyederhanaan model dan proses penyempurnaan sambil berjalan atau learning by doing (Alexander and Hughes 2017). Untuk mendorong IMTA dari skala percontohan menjadi skala industri dibutuhkan serangkaian kajian, edukasi dan penyesuaian aturan untuk meyakinkan pelaku usaha dan pembudidaya terhadap risiko usaha yang dihadapi (Alexander et al. 2016). Sebagai salah satu penyedia bahan yang akan dikonsumsi manusia maka isu keamanan pangan juga diintegrasikan dalam pengembangan suatu IMTA (Rosa et al. 2020).

\section{KESIMPULAN DAN SARAN}

Berdasarkan perkembangan dan tingkat adopsi teknologi budidaya lobster di kalangan pembudidaya dan pelaku usaha, maka perlu dibuat segmentasi usaha. Usaha pendederan dengan risiko yang masih relatif besar perlu dilaksanakan oleh unit pelaksana teknis (UPT) Direktorat Jenderal Perikanan Budidaya, sedangkan segmen usaha pembesaran lobster di KJA laut dengan risiko yang lebih kecil melibatkan masyarakat atau pembudidaya dan pelaku 
usaha. Pengembangan budidaya lobster berbasis multi tropik dapat dilaksanakan pada skala unit atau kawasan budidaya yang relatif kecil (kategori IMTA) dan skala kawasan budidaya yang lebih luas (kategori RIMTA). Hal ini untuk mewujudkan keberlanjutan pengembangan jangka panjang, mengoptimalkan pemanfaatan sumberdaya, meningkatkan penerimaan pembudidaya dan pelibatan masyarakat, sekaligus sebagai kontribusi perikanan budidaya dalam mitigasi emisi gas rumah kaca. Beberapa komoditas ekstraktif yang dapat dibudidayakan bersama lobster adalah rumput laut, kekerangan, teripang dan beberapa jenis ikan bertropik level rendah.

Untuk pengembangan budidaya lobster dibutuhkan penelitian terkait pakan yang efektif untuk benih dan pembesaran serta manajemennya, parameter lingkungan yang optimal, metode budidaya, jenis hama dan penyakit lobster serta penanggulangannya. Dalam rangka penerapan IMTA pada unit dan RIMTA pada kawasan budidaya lobster, dibutuhkan penelitian untuk mendapatkan komposisi (jenis dan volume/luasan) komoditas ekstraktif yang efektif dan bernilai ekonomis serta pengelola kawasan khusus RIMTA.

\section{DAFTAR PUSTAKA}

Ahmed N, Thompson S and Glaser M. 2018. Global aquaculture productivity, environmental sustainability, and climate change adaptability. Environmental Management 63:159-172. https://doi.org/10.1007/s00 267-018-1117-3.

Alexander KA, Potts TP, Freeman S, Israel D, Johansen J, Kletou S, Meland M, Pecorino D, Rebours C, Shorten M and Angel DL. 2015. The implications of aquaculture policy and regulation for the development of integrated multitrophic aquaculture in Europe. Aquaculture 443:16-23. https://doi.org/ 10.1016/j.aquaculture.2015.03.005.

Alexander KA, Angel D, Freeman S, Israel D, Johansen J, Kletou D, Meland M, Pecorino D, Rebours C, Rousou M, Shorten M and Potts T. 2016. Improving sustainability of aquaculture in Europe: stakeholder dialogues on integrated multi-trophic aquaculture (IMTA). Environmental Science \& Policy 55:96-106. https://doi.org/10.1016/j.envsci.2015.09.006.

Alexander KA and Hughes AD. 2017. A problem shared: technology transfer and development in European integrated multi-trophic aquaculture (IMTA). Aquaculture 473:13-19. https://doi.org/10.1016/j.aquaculture.2017.01. 029.

Anissah U, Pamungkas A, Waryanto dan Sukoraharjo SS. 2015. Uji efektivitas kompartemen dasar untuk pembesaran lobster pasir (Panulirus homarus) di Pantai Sepanjang, Kabupaten Gunung Kidul. Jurnal Kelautan Nasional 10(2):91-102. 
[Bappenas] Badan Perencanaan dan Pembangunan Nasional. 2021. Penilaian kegiatan pembangunan ketahanan iklim sektor kelautan dan pesisir: subsektor pesisir. Bappenas. Jakarta.

Ben-Ari T, Neori A, Ben-Ezra D, Shauli L, Odintsov V and Shpigel M. 2014. Management of Ulva lactuca as a biofilter of mariculture effluents in IMTA system. Aquaculture 434:493-498. https://doi.org/10.1016/j.aquaculture. 2014.08.034.

Chary K, Aubin J, Sadoul B, Fiandrino A, Coves D and Callier MD. 2020. Integrated multi-trophic aquaculture of red drum (Sciaenops ocellatus) and sea cucumber (Holothuria scabra): assessing bioremediation and life-cycle impacts. Aquaculture 516(734621):1-17. https://doi.org/10.1016/j.aqua culture.2019.734621.

Cubillo AM, Ferreira JG, Robinson SMC, Pearce CM, Corner RA and Johansen J. 2016. Role of deposit feeders in integrated multi-trophic aquaculture-a model analysis. Aquaculture 453:54-66. https://doi.org/10.1016/j.aqua culture.2015.11.031.

Galasso HL, Lefebvre S, Aliaume S, Sadoul B and Callier MD. 2020. Using the dynamic energy budget theory to evaluate the bioremediation potential of the polychaete Hediste diversicolor in an integrated multi-trophic aquaculture system. Ecological Modelling 437(109296):1-10. https://doi. org/10.1016/j.ecolmodel.2020.109296.

Granada L, Lopes S, Novais SC and Lemos MFL. 2018. Modelling integrated multitrophic aquaculture: optimizing a three trophic level system. Aquaculture 495:90-97. https://doi.org/10.1016/j.aquaculture.2018.05.029.

Grosso L, Rakaj A, Fianchini A, Morroni L, Cataudella S and Scardi M. 2021. Integrated multi-trophic aquaculture (IMTA) system combining the sea urchin Paracentrotus lividus, as primary species, and the sea cucumber Holothuria tubulosa as extractive species. Aquaculture 534(736268):1-11. https://doi.org/10.1016/j.aquaculture.2020.736268.

Handa A, Min H, Wang X, Broch OJ, Reitan KI, Reinertsen H and Olsen Y. 2012. Incorporation of fish feed and growth of blue mussels (Mytilus edulis) in close proximity to salmon (Salmo salar) aquaculture: implications for integrated multi-trophic aquaculture in Norwegian coastal waters. Aquaculture 356-357:328-341. https://doi.org/10.1016/j.aquaculture. 2012.04.048.

Hossain M, Mostafiz, Ahamed S, Hassan M, Ariful I, Abdul N, Enamul H and Akter T. 2021. Assessing cage culture potentiality of long whiskers catfish, Mystus gulio (Hamilton, 1822) in relation to climate change adaptation in Bangladesh coast. Journal of Applied Aquaculture 1-16. https://doi.org/10. 1080/10454438.2021.1881683. 
Israel D, Lupatsch I and Angel DL. 2019. Testing the digestibility of seabream wastes in three candidates for integrated multi-trophic aquaculture: Grey mullet, sea urchin and sea cucumber. Aquaculture 510:364-370. https://doi.org/10.1016/j.aquaculture.2019.06.003.

[KKP] Kementerian Kelautan dan Perikanan. 2021a. BKIPM siapkan rencana kerja ekspor lobster ukuran konsumsi [internet]. Tersedia di: https:// kkp.go.id/bkipm/artikel/.

[KKP] Kementerian Kelautan dan Perikanan. 2021b. KKP terus optimalkan potensi marikultur [internet]. Tersedia di: https://kkp.go.id/djpb/artikel/.

Kleitou P, Kletou D and David J. 2018. Is Europe ready for integrated multitrophic aquaculture? A survey on the perspectives of European farmers and scientists with IMTA experience. Aquaculture 490:136-148. https://doi.org/10.1016/j.aquaculture.2018.02.035.

Lamprianidou F, Telfer T and Ross LG. 2015. A model for optimization of the productivity and bioremediation efficiency of marine integrated multitrophic aquaculture. Estuarine, Coastal and Shelf Science 164:253264. https://doi.org/10.1016/j.ecss.2015.07.045.

Largo DB, Diola AG and Marababol MS. 2016. Development of an integrated multi-trophic aquaculture (IMTA) system for tropical marine species in southern cebu, Central Philippines. Aquaculture Report 3:67-76. https:// doi.org/10.1016/j.aqrep.2015.12.006.

Nelson EJ, MacDonald BA and Robinson SMC. 2012. The absorption efficiency of the suspension-feeding sea cucumber, Cucumaria frondosa, and its potential as an extractive integrated multi-trophic aquaculture (IMTA) species. Aquaculture 370-371:19-25. https://doi.org/10.1016/j.aquacul ture.2012.09.029.

Neori A, Troell M, Chopin T, Yarish C, Crichley A and Buschmann AH. 2012. The need for a balance ecosystem approach to blue revolution aquaculture. Environment: Science and Policy for Sustainable Develoment 49(3):36-43. https://doi.org/10.3200/ENVT.49.3.36-43.

Park M, Shin SK, Do YH, Yarish C and Kim JK. 2018. Application of open water integrated multi-trophic aquaculture to intensive monoculture: A review of the current status and challenges in Korea. Aquaculture 497:174-183. https://doi.org/10.1016/j.aquaculture.2018.07.051.

Raul C, Pattanaik SS, Prakash S, Vidya SK and Bharti S. 2020. Greenhouse gas emissions from aquaculture systems [internet]. Tersedia di: https:// www.was.org/.

Reid GK, Chopin T, Robinson SMC, Azevedo P, Quinton M and Belyea E. 2013. Weight ratios of the kelps, Alaria esculenta and Saccharina latissima, required to sequester dissolved inorganic nutrients and supply oxygen for 
Atlantic salmon, Salmo salar, in integrated multi-trophic aquaculture systems. Aquaculture 408-409:34-46. https://doi.org/10.1016/j.aquacul ture.2013.05.004.

Rifqi M, Widigdo B, Wardiatno Y, Mashar A and Adianto W. 2020a. The daily variance of $\mathrm{CO}_{2}$ and $\mathrm{CH}_{4}$ emission from shrimp ponds. IOP Conference Series: Earth and Environmental Science 420 (2020) 012026. https:// doi.org/10.1088/1755-1315/420/1/012026.

Rifqi M, Widigdo B, Wardiatno $\mathrm{Y}$ and Mashar A. 2020b. $\mathrm{CO}_{2}$ and $\mathrm{CH}_{4}$ flux from the water-air interface of three shrimp culture technologies. AACL Bioflux 13(2):605-617.

Rosa J, Lemos MFL, Crespo D, Nunes M, Freitas A, Ramos F, Pardal MA and Leston S. 2020. Integrated multitrophic aquaculture systems - potential risks for food safety. Trends in Food Science \& Technology 96:79-90. https://doi.org/10.1016/j.tifs.2019.12.008.

Salin KR and Ataguba GA. 2018. Aquaculture and the environment: towards sustainability. In: Hai FI, Visvanathan C and Boopathy R. 2018. Sustainable Aquaculture. Springer Nature. Switzerland.

Sans-Lazaro C and Sanches-Jerez P. 2020. Regional integrated multi-trophic aquaculture (RIMTA): spatially separated, ecologically linked. Journal of Environmental Management 271(110921):1-6. https://doi.org/10.1016/ j.jenvman.2020.110921.

Shi H, Zheng W, Zhang X, Zhu M and Ding D. 2013. Ecological-economic assessment of monoculture and integrated multi-trophic aquaculture in Sanggou Bay of China. Aquaculture 410-411:172-178. https://doi.org/ 10.1016/j.aquaculture.2013.06.033.

Shpigel M, Ben-Ari T, Shauli L, Odintsov V and Ben-Ezra D. 2016. Nutrient recovery and sludge management in seabream and grey mullet co-culture in integrated multi-trophic aquaculture (IMTA). Aquaculture 464:316-322. https://doi.org/10.1016/j.aquaculture.2016.07.007.

Shpigel M, Shauli L, Odintsov V, Ben-Ezra D, Neori A and Guttman L. 2018. The sea urchin, Paracentrotus lividus, in an integrated multi-trophic aquaculture (IMTA) system with fish (Sparus aurata) and seaweed (Ulva lactuca): nitrogen partitioning and proportional configurations. Aquaculture 490:260-269. https://doi.org/10.1016/j.aquaculture.2018. 02.051.

Sterling AM, Cross SF and Pearce CM. 2016. Co-culturing green sea urchins (Strongylocentrotus droebachiensis) with mussels (Mytilus spp.) to control biofouling at an integrated multi-trophic aquaculture site. Aquaculture 464:253-261. https://doi.org/10.1016/j.aquaculture.2016.06.010. 
Troell M, Joyce A, Chopin T, Noeri A, Buschmann AH and Fang JG. 2009. Ecological engineering in aquaculture - potential for integrated multi-tropic aquaculture (IMTA) in marine offshore systems. Aquaculture 297(1-4):19. https://doi.org/10.1016/j.aquaculture.2009.09.010.

Valenti WC, Kimpara JM, Preto B de L and Moraes-Valenti P. 2018. Indicators of sustainability to assess aquaculture systems. Ecological Indicators 88:402413. https://doi.org/10.1016/j.ecolind.2017.12.068.

Visch W, Kononets M, Hall POJ, Nylund GM and Pavia H. 2020. Environmental impact of kelp (Saccharina latissimi) aquaculture. Marine Pollution Bulletin 155(110962):1-12. https://doi.org/10.1016/j.marpolbul.2020.110962.

Yokohama H. 2012. Growth and food source of the sea cucumber Apostichopus japonicus cultured below fish cages - potential for integrated multitrophic aquaculture. Aquaculture 372-375:28-38. https://doi.org/10.1016 /j.aquaculture.2012.10.022.

Yu LQJ, Mu Y, Zhao Z, Lam VWY and Sumaila UR. 2017. Economic challenges to the generalization of integrated multi-trophic aquaculture: An empirical comparative study on kelp monoculture and kelp-mollusk polyculture in Weihai, China. Aquaculture 471:130-139. https://doi.org/10.1016/j.aqua culture.2017.01.015. 